\title{
The Hero beyond the Mask: Discussing Children's Referential Problems in Literary and Audiovisual Texts
}

\section{Marcio $V^{*}$}

University for the Development of the High Valley of Itajaí-UNIDAVI, Brazil

*Corresponding author: Márcio Danilo Mota Varela, University for the Development of the High Valley of Itajaí-UNIDAVI, Rua Osvaldo Reis, 2000; Cond. Max Hauss - Praia Brava 1/Itajaí-SC, Tel: 84981107977; E-mail: marciovarela7@gmail.com

\section{Review Article \\ Volume 3 Issue 1}

Received Date: December 21, 2017

Published Date: January 24, 2018

\section{Abstract}

The main objective of this article is to discuss critically children's referential problems in literary and audiovisual texts. As many know children's intuitive age group (4-8 y.o.) present a unique developmental features that are embodied by the primitivist aesthetics principles. For this reason children within such age group present special psychological needs for which deserve close attention from all agents involved in child's cultural productions, especially in literary and audiovisual texts. For such texts are referenced by many as the ones with which children have more contact, thus, this article starts from the referential problems children may face during the reading process. It makes use of the classic children's novel: the Little Prince written in 1943 by the French classic author Antoine de Saint-Exupéry, as sample of analysis. The analysis occurs in both versions of the story (literary and audiovisual) from which is also possible to identify some key referential problem for children's intuitive age group. In order to demonstrate how such children age group realizes their sense of story, this article presents a narratological approach based on the primitivist aesthetics. The concept for heroism, in turn, plays key role in the analysis in the form of four interchanging frameworks towards revealing the specific psychological needs children have during the intuitive age of development. As a result, the article concludes that children's intuitive age group tend to realize their sense of story by following the intuitive conceptual references left along the stages of hero's journey. If any prime intuitive concept (animism, artificialism, and finalism) is missing in the narrative, so it can provoke referential problems in a consecutive order affecting the overall understanding of the story, consequently not satisfying children's main psychological needs.

Keywords: Primitivism; Aesthetics; Children's Literature; Referential Problems

\section{Introduction}

There is no perfect text. This may sound too obvious for some, but for others may not. Many people from the crowd do think that perfect texts exist. Prizes and influent voices that help testify the creditability of texts worldwide boost the significance for such perception of perfection around classic texts. As though it was a kind of divine gift, such texts pass almost thoroughly as a miraculous message from the gods to their selected 


\section{Psychology \& Psychological Research International Journal}

author's mind. For instance, the inspiration during Romanticism times seemed to matter more than transpiration for the Art per se belonged to a divine presence. The large discussion about what the art is made of has been echoing in human history from the classic Greek times now. The result of such discussions may be observed mainly in the form of controversies, which helped create a Manichean dichotomy the origins of author's talent, and how do they conceive their art craft.

Whatever the controversies might be, the fact of the matter is that today's popular understanding about literary art is still full of credulities. As such, it only helps keep up a status quo of a perfective perception over classic literary materials. It does not mean here neither that classic literature are not healthy and respected, nor that the classic authors do not deserve all prestige they do from the public opinion, but only to say that there is no perfect text. Although miracles may still exist in one's mind to explain the power of the extraordinary, there is always a slight amount of skepticism that tends to be provocative. By being provocative, this article tends to be positive and helpful towards new insights that may promote better understanding about children's classic literature. As such, the article pushes the limits of the literary art per se forwardly to reveal interesting breakups that help to understand the real importance and impact of any children's literary text [1]. In short, by exploring small pieces of the whole is possible to comprehend not just the complexity inherent to any children's classic literary material, but also to improve new readings to find better solution to problems that seem persistent along children's literature history.

Therefore, the analysis over the story of the Little Prince, written in 1943 by Antoine de Saint-Exupéry, is to serve as excerpt that children's classic literary may present imperfections for some children's age group. However, by imperfection this article does not mean errors, but a lack of space that some subjects cannot have access into it. Thus, text herein means space, where the subjects insert themselves in. Only from such perceptive is possible to identify the so-called children's referential problems in children's classic literature and audiovisual materials. For children's classic literary texts tend to be taken for granted as synonym of perfection into the popular point of view, the analysis here of the Little Prince's story is critical and pragmatically discussed over four interchanging framework of analysis: the Mythological Hero's Journey; the Magic Realism Theory; the Functions of Emotions; Children's Intuitive Concepts.

The reason for using such frameworks is due to intimate relationship that children's literature have with the primitivist aesthetical point of view. After the brothers Grimm decided to adapt folktales to satisfy children's aesthetical principals, children's literature has been shaped at large connection with a special way of writing and reading texts [2-8]. The mythological heritages in children's text furnished the four frameworks of analysis with the same indicators, which were based on that we call as the primitivist aesthetic. Mythical structures are the pillar of our frameworks of analysis. They are used not exactly to hide or change realities, but rather to reveal and demonstrate pragmatically hidden elements that only with their lenses one may depict from the texts.

Again, there is no perfect text whatsoever. Any text, especially children's classic literary text, should be revised as many times as possible. In relation to our objectives, the revision is made not exactly to deny the importance of children's classic text, but only to demystify some issues about the referential problems children may have in any text (space) that do not offer them the means to access into it. Ultimately, our revision on the Little Prince's story is just to bring light into the importance in satisfying children's psychological needs by offering them proper conceptual references for them to access the literary texts as subjects who have limited experiences. The methodological procedures made for this article checked out the imperfection in Little Prince's text, but it can be used for any other literary text. For this reason, revising classic texts according to this method is by far a good way to improve the reading process of the text. It is, therefore, by following this thinking that this article shed lights on what do make and do not make a good children's text to be as such. The article reveals, in another words, the hidden secrets in the narrative of Little Prince in both versions of its story (literary and audiovisual) in order not to reaffirm the sense of perfection, but reaffirm the sense of appropriateness children's classic text is to offer over different children's age group.

Lastly, for the purpose of this article, children's intuitive age group is the subjective focus of the analysis. By children's intuitive age group, we understand its close aesthetical relation to the magic elements and primitivist peculiarities that are likely to be translated into a special conceptuzalition process [9-11]. Children's Magical Realism is both the term and the theory that best defines the conduct characteristics of children from ages 2 to 10 years old [12,13]. However, for the most impacting intuitive moments in children development occurs in between the ages of 4 for 8 years old; therefore, only such ages are considered for the analysis. The most remarkable trace of this stage in children's life is the qualitative intertwinement between primitivist aesthetic and its use 


\section{Psychology \& Psychological Research International Journal}

of narratives towards cognitive organization of individual and collective experiences $[7,14,15]$.

Therefore, to close understand some key assumptions that for so long have proved persistent about children's referential problems in literary and audiovisual texts, and how such texts may or may not improve children's psychological development, the purpose of this study was to answer the three following questions: 1)How do children in the intuitive age realize their concept of story? 2) Which kinds of referential problems children are likely to incur, as texts are not suitable for their own conceptualization process? 3) How do such problems may be identified in classic children's literature? As a result, the analysis proved that the socio-psychological advantages are various. Thus, for taking in consideration solely our age group, the analyses indicated that children should be stimulated to develop their natural intuitive emotional intelligence towards gradual social adaptation, inasmuch as children should have their cognitive process adapted into suitable texts, such as the Exupéry's Little Prince whose influence and prestige have remained remarkable over generations worldwide. With focus on children's intuitive age, the primitivist aesthetic demonstrated pragmatically a narratological benefit to children's classic literature and audiovisual material as it identifies several referential problems towards the psychological needs in children's intuitive age group.

\section{Method}

The methodological procedure considered four complementary and inter depend frameworks developed throughout a process of triangulation, which considered simultaneously both research approaches: quantitative and qualitative. Thus, starting from a Qualitative Content Analysis, a suitable categorization for the magic concepts was capable to offer significant amount of data that started indicating the need for filtering as the primitivist elements were previously set up in the form of a list of conceptual references. As such, the referential elements found were limited to solely those ones considered as the most common to the intuitive age group (animism, artificialism, and finalism). From this perspective the theoretical contribution from the Piagetian studies of children's cognitive development provided guidance on the importance of how the biological functions operate when stimulated by both a suitable or non-suitable conceptualization process of references during the intuitive age group.

Such perspective made possible for the identification of potential relationships, which were mapped out later and separated into both common and different conceptual references. After the literary text had provided the research with conceptual references, it served to arrange the data into conceptual categories. So that, it created a concise intuitive string of concepts that were tacitly expressed in the text, and somehow presented at coherent relationship level in terms of intuitive conceptualization and meaning process. The application of a Relational Analysis served as a filter for the conceptual references without which would have resulted very difficult to turn them into basic intuitive concepts. Thus, the concepts were used to answer children's simple intuitive questions according to their psychological needs. That was a paramount requirement to the research, for it was a suitable set of intuitive concept towards the satisfaction such psychological. At this level, the research method tried to offer a new narratological approach that could be used on different children's cultural materials, but with especial focus to the interplay between literary and audiovisual texts. Explaining a bit more about the filtering process, it is possible to say that due to the vast amount of data extracted from within the textual elements, the conceptual strings guided our readings towards children's textual reference in the story. It worked quite significantly on as a flexible semantic approach over the conceptual relationships that were respectively formed by the Relational Analysis.

From that perspective and on, the research method shifted slightly its focus in order to encompass as many intuitive elements as possible. It was, then, the time to apply the four complementary theoretical frameworks of analysis, which had already been proved being consistently suitable for this kind of textual analysis [13]. Therefore, the four complementary framework used were respectively 1) the Mythological Hero's Journey (MHJ); 2) the Magic Realism Theory; 3) Functions of Emotions; 4) Children's Intuitive Concepts. These complementary frameworks made possible to stand out the referential scope within the narrative of The Little Prince story in its both versions literary and audiovisual. Afterwards, the four complementary frameworks showed the specific conceptual information concerning numbers of frequency, categorization, localization, and detailed description of the magic realistic elements (animism, artificialism, and finalism) identified in the narrative.

Step 1- Reducing the text to categories and codes for concept patterns.

The reduction of the text into categories and codes represented a systematic procedure that considered the questions concerning primarily with children's referential text problems within the Intuitive Age (4-8 years old). Thus, four frameworks of analysis: Mythological Hero's 


\section{Psychology \& Psychological Research International Journal}

Journey; Magic Realism Theory; Functions of Emotions; Children's Intuitive Concepts were put together in order to generate conceptual codes for the systematic Relational Analysis of the narrative. Accordingly, among the three subcategories of relationships (Affect Extraction, Proximity Analysis, and Cognitive Mapping), the Cognitive
Mapping offered a much broader scope of actuation for attempting to take the two other processes further. While in affective and proximal analysis the focus is primarily on the preserved order of the text, cognitive mapping, on the other hand, operated by focusing on a cognitive model towards an overall meaning of the texts.

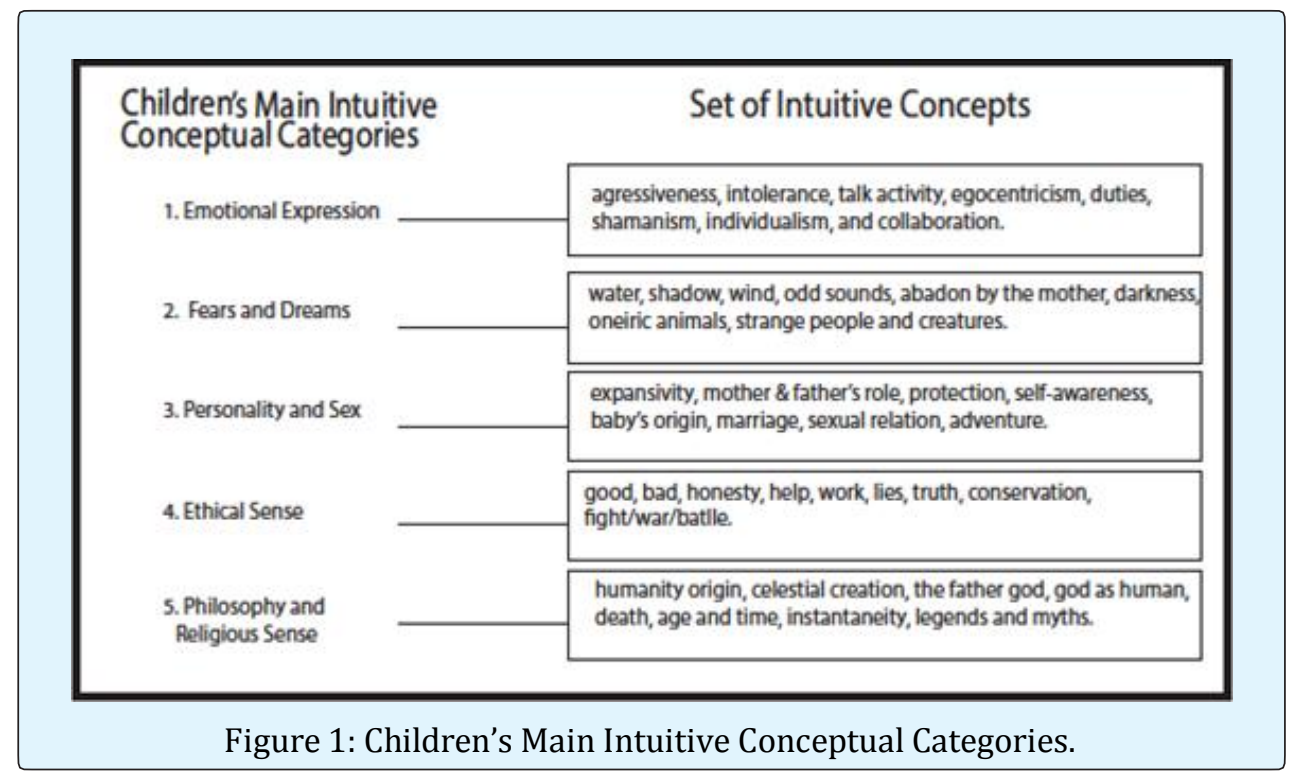

That was responsible to enable visual representations through a graphic map of relationships. Afterwards, the texts were reduced into five main conceptual categories. Such categories corresponded solely to children's main psychological needs during the intuitive age. Afterwards, each category generated approximately from eight to nine intuitive concepts in each conceptual set, which ended up summing forty-two concepts altogether, as follows:

Step 2 - Exploration for relation patterns among Concepts.

The next procedure defined the type of conceptual relation to be explored; then, the conceptualization process in children's intuitive conceptualization. For this, among the three methods available for exploring relational concepts by means of a Relational Analysis (Strength of relationships, Sign of a relationship, and Direction of the relationship), the Sign of a Relation proved to be suitable as to whether or not the concepts encoded were positively or negatively related to children's referential problems in the literary and audiovisual texts. Afterwards, the kinds of conceptual relations existing in the story of the Little Prince were revealed by means of a pragmatic approach method, which considered a semiotic interpretation of the mythological figures embedded in the story. As such, the sematic values obtained from such semiotic efforts condensed its significance values into six main archetypal characters: Hero, Mentor, Threshold guardian, Herald, Shape shifter, and Shadow. Those archetypal characters are the same presented in the M.H.J. structure, in the relational patterns between the types of emotions (Background, Basic and Social), and in their corresponding narratological functions (negative, positive and neutral), which launched signs about how the evolution of the hero in the narrative were performed. The semantic approach served as a relational pattern for children's textual reference as based on Children's Conduct Characteristic (C.C.C.) in the intuitive age (Leveled - ages: 4, 5, 6 and 61/2; Unleveled - ages: 41/2and 51/2; Reserved - ages: 7 and 71/2; Expansive - age: 8).Ultimately, with that sort of approach it was possible to follow the psychological development of the hero in the narrative. It made possible at the same time to measure and describe probable deviances in children's assessment of the concepts dealt in each stage of M.H.J. structure. In other words, M.H.J. structure worked to outline the overall C.C.C in both versions (literary and audiovisual) of the story of the Little Prince.

\section{Step 3 - Performance of a Statistical Analysis}

At this level, the figures described were statistically presented as to how the variables are distributed, located, and controlled along the conceptual relationships that 


\section{Psychology \& Psychological Research International Journal}

had already been previously extracted from the sample materials. A Descriptive Statistic showed frequency accounts in terms of positive and negative values that led us to know the standard intuitive conceptual deviations. The method considered the relationships among variables by dealing with correlations using values encoded by the software Excel 2016.

\section{Step 4 - To Map out the Representations}

Afterwards, the research continued mapping out the concepts as well as its relations. It used, therefore, a Mental Mode, which is offered by the Cognitive Science. In order to create such model, the texts needed firstly to be converted into a map, so that the concepts and conceptual relationships should later be capable to generate relevant figures to identify their levels of incidence towards the intuitive conceptualization process along the literary and audiovisual text. By following this methodological stream, the map showed the intuitive concepts arranged and distributed along the different stage of the mythological hero's journey. It consequently made possible to reveal, too, all kinds of relationships formed by the four theoretical frameworks. In other words, the Cognitive Mapping improved the semantic connections across the textual elements within the so-called Map of Analysis, which allowed exploring comparatively how meanings conflicted between the perspectives of the author to the perspectives of children's intuitive age group by means of a list of our set of intuitive concepts.

\section{Results}

\section{Framework 1: The Mythological Hero's Journey}

Within the story of the Little Prince indicates many animistic values that help significantly the narrative to coordinate the dramatic evolution of the hero $[16,17]$. For instance, as we consider only the most impacting stages of the hero, it is possible to observe that along the stage 1,4 , 6 , and 10children's intuitive conceptualization process had the most meaningful moments for dealing drastically with basic intuitive concepts. Thus, for such conceptualization the incidence marks indicated $20 \%$ for animism, $15 \%$ for artificialism, and $8 \%$ for finalism). However, along the other stages not mentioned yet, the animist as well as the other intuitive concepts dropped down so drastically their occurrence numbers to values lower than $2 \%$. From that perspective, it is possible to assume that the literary text may become seldom confused for the reading process as to children's intuitive references, which consequently may cause referential problems towards the satisfaction for their psychological needs. A reasonable explanation for such potential children's referential problem may be found in the lack for animistic concepts, especially at the end of the story when children mostly need to connect their fictional context to their regular routines. Thus, it is also possible to observe the lack of animistic values in the graphic of the Figure 2 below.

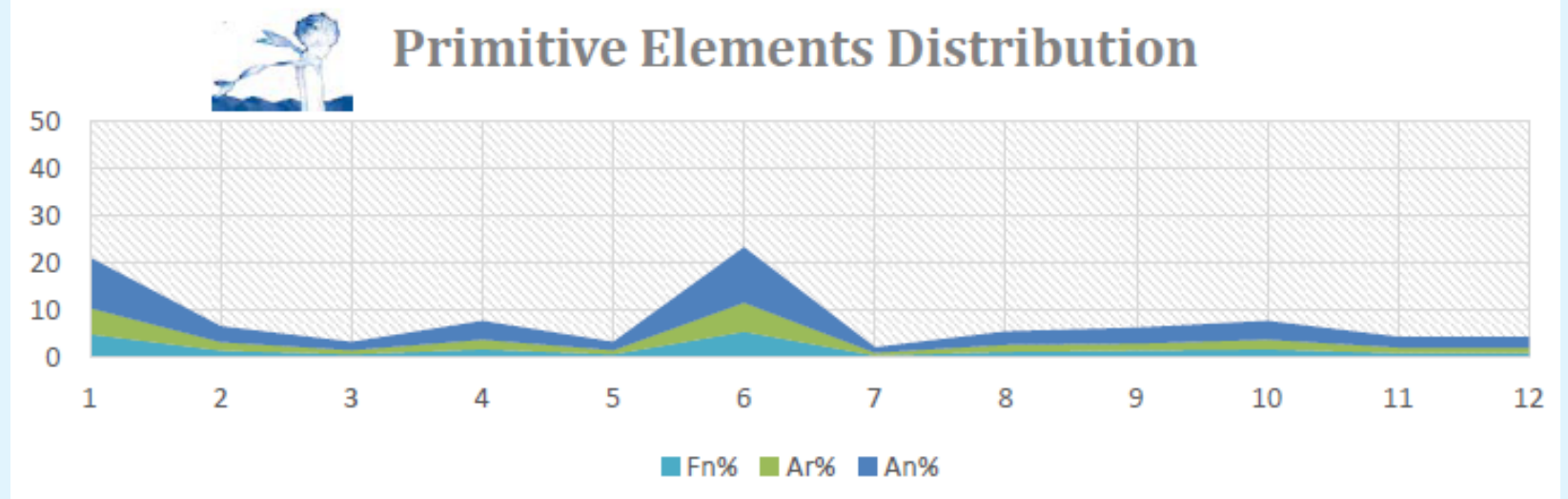

Figure 2: Distribution of the three prime primitive concepts along the narrative.

Despite the fact that the distribution of the three prime primitive concepts did not have the same values along the literary text, the intuitive concepts remained present due to the animistic (An) values. Again, for it reduced its occurrence at the end of the story so drastically, it indicated lack of reference for children's conceptualization process, as we had previously pointed out. However, for getting closer to the specific points of the problem, it is possible to highlight that the lack for the basic intuitive conceptualization occurred only at those specific stages of the third act. Additionally, another reason may be described by the application of a realistic 


\section{Psychology \& Psychological Research International Journal}

"death-and-life" situation from which made the end of the story become sad looking instead of happy. Thus, the type of realism applied on that it does not sufficiently corresponded to children's intuitive age responses, even though we became aware of the resurrection of the Little Prince as he got back up to his planet.

Thus, the application of the first framework on the literary text indicated a quite different result from results found in its audiovisual version. It seemed that the referential problems were fixed, even though all the three prime primitivist concepts did not vary much from those ones of the book. Therefore, the reason identified for the fixing of the referential problems found was due to the intensive and dramatic involvement of the other archetypal characters, as it can be seen in the graphic of the Figure 3 bellow.

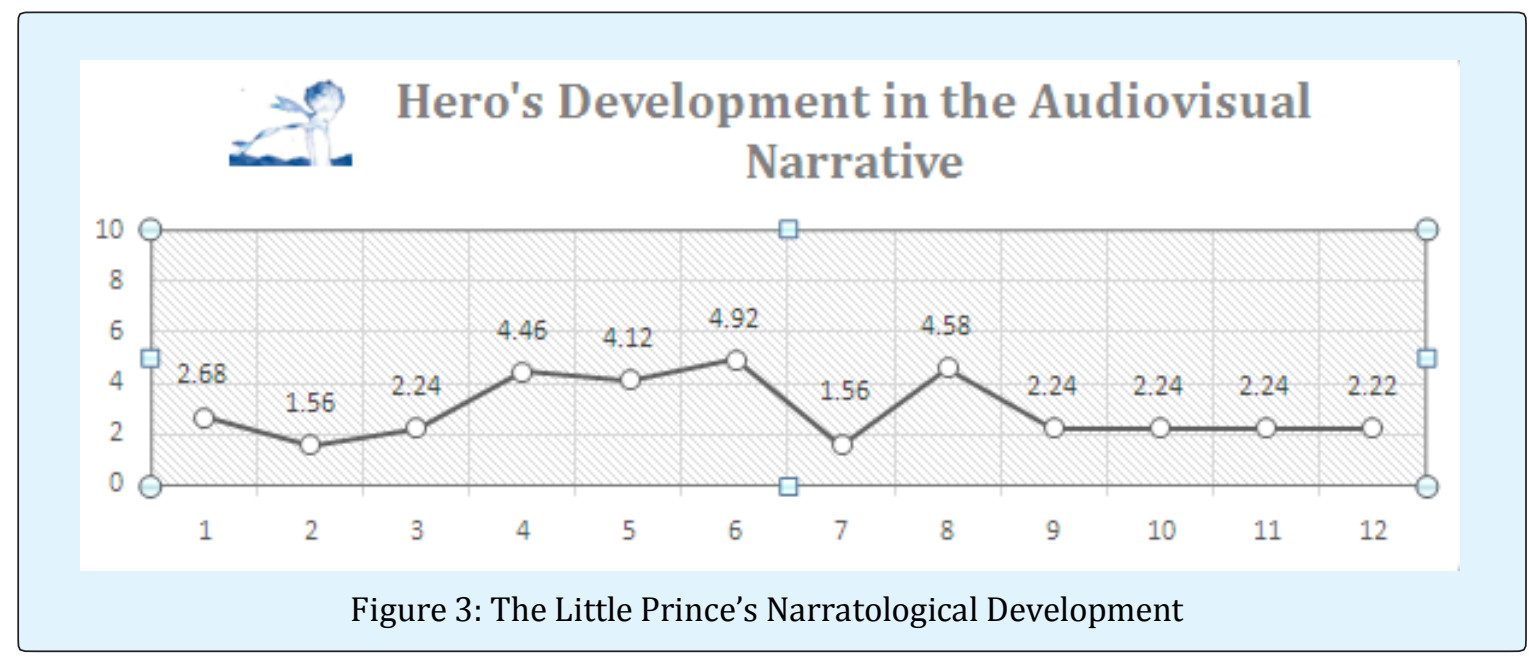

Hero (Little Prince $=1,56 \%$ );

Mentors (the Pilot $=4,46 \% ; 4,12 \% ; 4,92 \% ; 4,58 \%$ and the Rose $=2,68 \%$, The Fox 2, 22\%)

Threshold Guardians (The Snake $1=2,24 \%$; Snake $2=$ 2, 24 (3 times in stages 9, 10, and 11))

Herald (The Rose $=2,68 \%, 2,22 \%$ )

Shape shifter (Snake 1 = 2, 24\%; the Fox 2, 22\%)

Shadow (The Special World $=1,56 \%$ )

Trickster (the Fox 2, 22\%)

The most active archetypal character in the audiovisual story other than the hero was the Mentors represented by the Pilot and the Rose. As both assumed several common psychological functions belonged to the figure of the hero, they worked together for the Little Prince's Development in Audiovisual Narrative. However, if we are to compare their participation with the literary narrative of original book, it is possible to affirm that the audiovisual text showed a more coherent child's psychological involvement with the story. That happens not only for the narrative has been based on a more frequent occurrence for the prime intuitive concepts, but also for the other archetypal characters along the filmic narrative give them support to keep up focusing on the intuitive age group, especially between ages 3 to 5 years old.
Aside from that, it is important to identifying how the values for children's intuitive concepts are distributed along both literary and audiovisual narratives. As such, the quantitative data from the first framework improved the qualitative aspect of the analyses as to the precise location for all primitivist concepts in both texts. Consequently, it is possible to assume that the stage 2 (The Call to Adventure),and the stage 7 (the Approach) both have presented the lowest intuitive conceptualization momentum in the narratives in which affected the ages of 2 years old. In second place appears the stages 1 (the Ordinary World), 3 (Refusal of the Call) and 9 (Reward), 10 (the Road Back), 11 (Resurrection), 12 (the Return with Elixir) that shifted a little bit its line of occurrence; it also affected the age of 2 years old. While in the literary narrative is possible to have a linear story as to such stages, in the audiovisual narrative the story has been told nonlinearly, which demands more focus and memory from the intuitive-age-group towards a reasonable referential contextualization. The stage 6 (Test, Allies and Enemies) scored two times more intuitive conceptualization involvement by means of the other archetypal characters than the stages previously quoted. Thus, the stage 6 in the audiovisual narrative is showed hyperbolically (as the majority of children's 


\section{Psychology \& Psychological Research International Journal}

stories do) the sense of adventure, where as in the book the stage 7 (The Approach) minimal participation for the construction of such intuitive sense. This is important to proof that the both narratives had an intensive narratological appeal to dramatic scenes that children within the intuitive age group are likely to conceptualize.

\section{Framework 2: The Theory of Magic Realism}

Comparatively to other classical child's novels that passed though the same methodological procedures, the Little Prince presented more intuitive concepts in its audiovisual narrative. For instance, among the other material analyzed in a 2012 Ph.D. dissertation [12], some well-known classic children's novels, such as Charlie and the Chocolate Factory (Roald Dahl, 1964), Momo (Michael Ende, 1968), or even The Jungle Book (Rudyard Kiplling, 1894) demonstrated less intuitive concepts in those narrative than the Little Prince does it. Therefore, it is possible to affirm that the narrative of the Little Prince in both literary and audiovisual texts present more suitable references for children's intuitive age conceptualization process. As all the three prime primitivist elements that are likely to be obtained from the theory of magic realism, the Little Prince's narrative demonstrates the prime primitivist elements activated and evenly distributed all along the M.H.J. stages. The only missing primitivist concepts are those ones related to some of the pictorial elements pointed by Menton (1999) [18]: the "UltraPrecise Focus", "Frigidity", and the Elimination of the Painting process. However, the referential problems identified basis themselves on the lack of some prime intuitive concepts rather than the magical element of the theory; so that, the missing conceptualization of the prime elements represented crucial intuitive references for complete Children's Conduct Characteristics (C.C.C.) in the intuitive age group. The C.C.C. type identified in the narrative of both the literary and the audiovisual texts correspond to L.U.R.E. (Leveled, Unleveled, Reserved, and Expansive), which stands for the hero's developmental process in the narrative, achieved 96\%. Such finding connects with the evolution of children's magic realism described on the graphic of the (Figure 3), where it demonstrates the involvement of the other archetypal characters for the hero's development. During the analysis, the only missing theoretical magic concept is the "Telluric and Human Unity", according to which the story misses to deal with strong philosophic senses for the satisfaction of children's intuitive psychological needs. Additionally, it does not make any relation to the Philosophy and Religion Sense of children, which are described and pointed out by the list of Children's Main Intuitive Conceptual Categories; consequently, its set of intuitive concepts (humanity origin, celestial creation, the father god, death, god as human, age and time, instantaneity, legends and myths) related to such category are not mentioned, according to this narratological analysis.

The referential problems identified in the stage $4,5,6$, and 8 may affect child's ages of $4 \frac{1}{2}, 4,5$, and $4 \frac{1}{2}$ years old as the graphic of the (Figure 4) shows below:

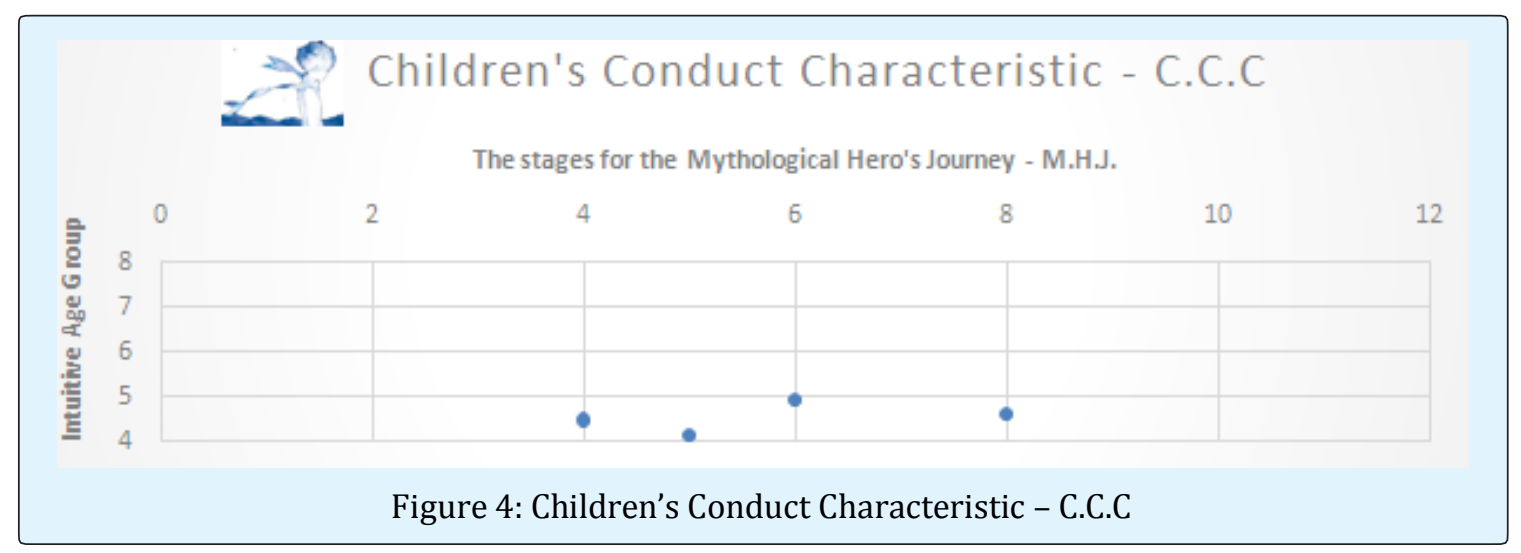

Regarding only the other elements of the magic realism as to its secondary elements, which sum 10 elements altogether(the Tradition as a Supreme Rule; the Mystic Notion of Causality; the Mythic Concept of Time; the Animist and Vitalist Concept; the Natural and Supernatural Concept; the Telluric and Human Unity; the Ontological Transformation Flow; the Concrete Logic; Ludic Element; Natural and Hyperbolic Tendency), which compound our Children's Magic Realism theory [12],are almost fully active in the narrative. The most active elements among such secondary elements are mainly the "Natural and Hyperbolic Tendency" and the "Ontological Transformation Flow", especially, as their concepts shifts its representations over events, creatures and realities in the narrative. The same happens to the "Representation of Reality" used as a general reference rule from the 


\section{Psychology \& Psychological Research International Journal}

factual world to the fictional one. As such, it did not change its structure within the hero's special world; therein, it did not present any sort of conflictive reference rules. The missing elements from the secondary elements (the Mystic Notion of Causality; the Mythic Concept of Time) testifies the lack of the prime intuitive elements pointed out by the Main Intuitive Conceptual Categories used for the analysis. Apart from such theoretical elements, all other primitivist concepts were found in a leveled status of incidence (tradition as a supreme rule; the natural and supernatural unity; the ontological transformation flowing; the concrete logic; the lucid element, and the natural and hyperbolical tendency).

Framework 3: Social Functions of Emotion Relatively, the Little Prince's narrative did not present many referential problems, despite the fact that the hero's development go along both textual narrative (literary and audiovisual) very much unstably. As such, it was identified only four referential problems located in the stages $4,5,6$, and 8 . The referential problems in both narratives connects with a) the hero's meeting with his self-consciousness represented by the mentors (The Rose, the Pilot, and at certain moments the Fox, as well),b) the hero's conflictive decision to cross the first threshold, c) the hero's approach to his life lesson, and c)the hero's proof of courage by going through his ordeal. From that perspective of analysis, the Little Prince is expected to solve his inner questions along the journey towards his psychological development. Accordingly, such moments in the narrative had to do with a kind of contextualization that escaped from the general rules of Little Prince's factual world, especially in the literary version of the story. The hero's performance observed through the emotional function corresponds to $96 \%$ in both versions of the narrative. Thus, it is closely observed only the problematic stages (The Meeting with the Mentor, Crossing the Threshold, The Approach, and the Ordeal) from which the hero's conducts characteristics varied drastically from an unleveled C.C.C. up to an expansive one.

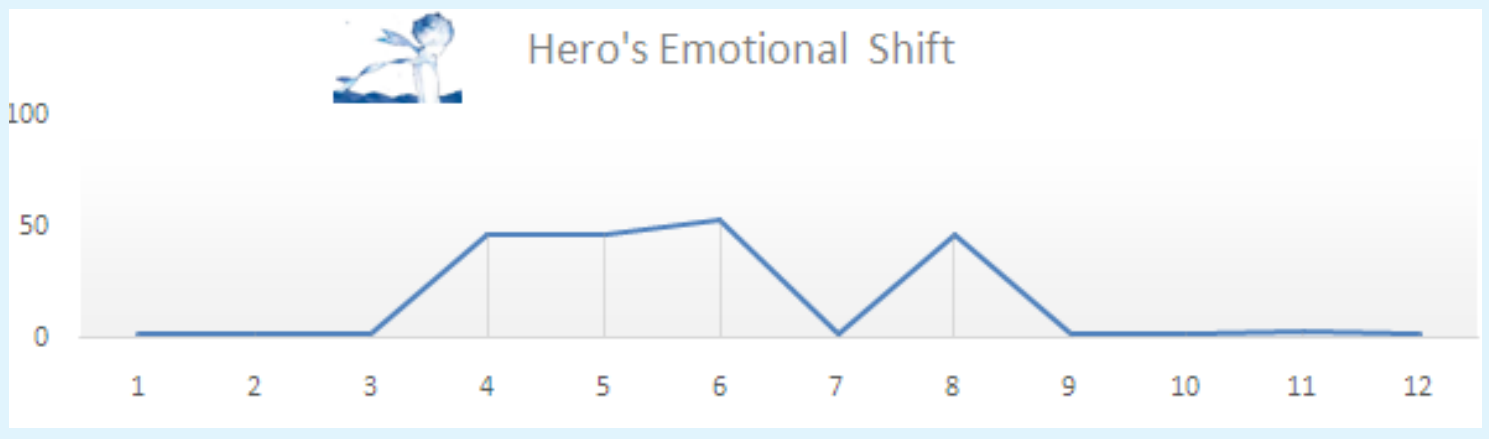

Figure 5: The Hero's Emotional Shift Representation

In Short, children's referential problems remained constantly out of children's intuitive conceptualization along the first stages of the second act. The lack of magical concepts concerning particularly, artificialism and finalism had a direct impact on children's referential problems, inasmuch as the lack of some concepts for children's philosophic and religious sense. Similarly, for the animistic values highly over came the other magical values throughout the problematic stages, there by disturbing its textual reference as well as provoking lack of stability towards a balanced-primitivistconceptualization process. Analysis observed that the absence for other magical concepts, from the secondary elements of the magic realism theory, in comparison with the high values of animism, hindered not only children's identification process with the story, but also with the social values that key for children conceptualize up to their socialization process. That by itself is problematic, mainly in the literary version where children do only have linguistic codes in the form of letters, pictures, and/or voices, depending on if the story is told for them. The audiovisual version of the story made possible to slightly fix such problems presenting visually a strong social conceptualization by means of a, too, strong heroism conceptualization. It was also observed that the type for the hero's representation is not what mattered more in the both narratives, but how the hero performed his conduct characteristics within a strong institutive conceptualization, even though such conduct characteristics have not been observed as being evenly distributed along the whole narrative. The analysis observed that the animistic values are equivalent to a "what", revealing all narratological means used in the story to express its special codes of accessibility into the unconsciousness of children's communicative process. Similarly, children's intuitive age group needed to be 


\section{Psychology \& Psychological Research International Journal}

introduced to a certain type of "why" belonging to finalism and a kind of "how "related to artificialism [9,1921]. The urge for a coherent contextualization, specially, at the beginning second act of the hero's journey, some others referential problems may occur quite significantly. For the weak identification process with the hero's emotional development, the Little Prince (the hero) demonstrate an emotional evolution quite different from a regular child. Being more like an adult's point of view, Little Prince may be identified as a negative character in the literary version, for the lack of other linguistic codes present in the audiovisual version analyzed.

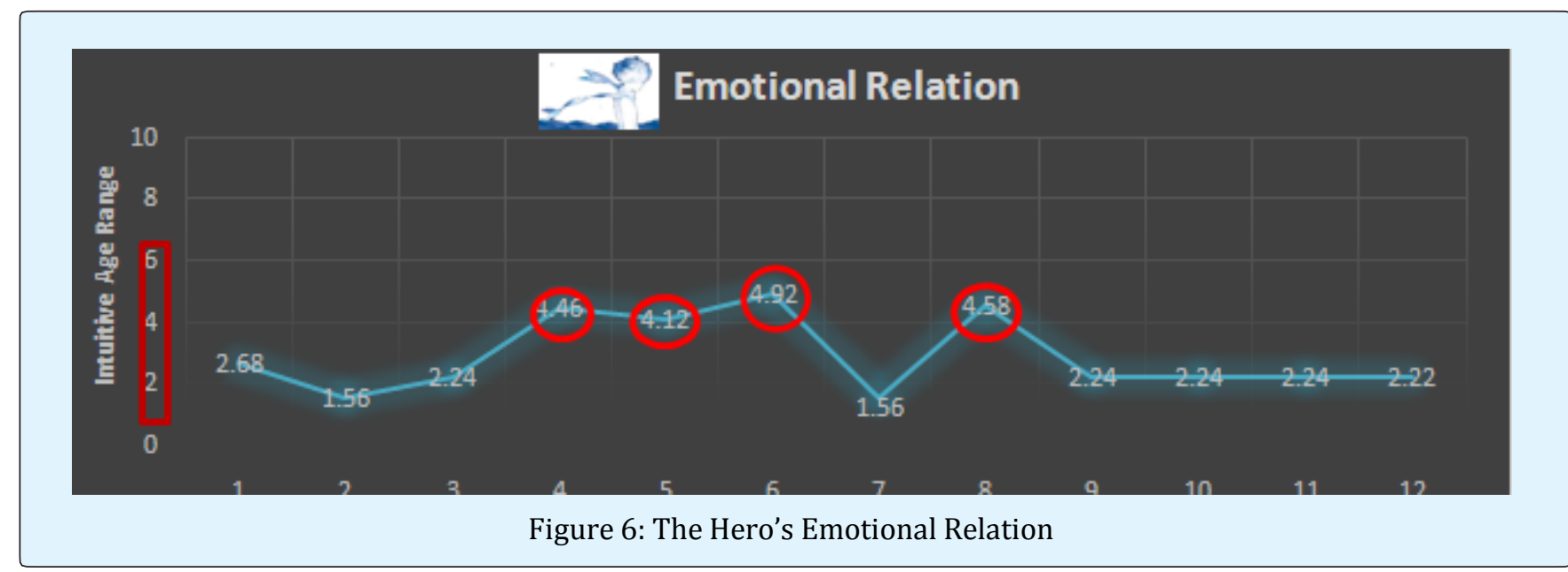

Thus, by explaining the developmental evolution of the hero, it is possible to affirm that the Little Prince's emotional evolution started the journey by being Neutral (normal) in terms of adult's conceptualization all along the stages $1,2,3$. Then, he became Positive in the stages 4 , 5,6 , and 8 matching perfectly with his unleveled conduct characteristic. In the stage 7Little Prince became drastically negative. Finally, from stages 9 to 12 Little Prince returns to his Neutral conduct, matching with his Expansive conduct after learning his lesson at the end of both narratives. However, the emotional relations accused also that Little Prince achieved numbers of expansiveness lesser than those expected for the intuitive age group. So, child's ages from 2 to 6years old were identified as being unlikely to comprehend the overall context of story in the specific stages, for the texts do not address entirely suitable intuitive concepts. Therefore, after calculating the data, thereby finding the specific C.C.C. for the hero's development, it was possible to demonstrate where there ferential problems were located along the hero's journey stages. They summed in both stories at least four main children's referential problems affecting those specific age groups. The unleveled conduct characteristic found in the Little Prince demands more attention and concentration from the intuitive age group, especially by the literary version of the story than the audiovisual material. According to the analysis on the intuitive concepts, children's intuitive age group may be affected mainly as the Little Prince appears to the audience for the first time shifting dramatically his C.C.C. from a total leveled manner towards an unleveled C.C.C.
That is true and goes on right in between the stage 6 and 7 , as both narratives (literary and audiovisual) did not present enough magic concepts. The theoretical and practical analysis made from the texts points out that children's intuitive age are much more likely to conflict with the character by losing interaction and identification with the story when occurs a weak assessment for the main intuitive conceptual references dealt in the story. That is very problematic for children's conceptualization process of the story, as children need to get into contact with the social rules of the factual world, as well as to the moral and ethical values that should present the same valuation account as they do for the fictional world.

\section{Framework 4: Pragmatic Relations among Children's Intuitive Concept.}

Other problematic situation referred to such probable children's lack of interest in the reception of the story may be found by means of the fourth pragmatic framework, which has been classified as a referential guide that goes through problems over the distribution of the emotion types of the hero. As such, it helps to explain why the hero's emotions may shift along the narrative. It also helps accuse when those emotions occurs along the stages of hero's journey. Aside from the four referential problems previously identified in the stages $4,5,6$, and 8 , where the hero presented a conflictive state of mind for the lack of intuitive concept (Figure 5). The referential problems that are caused for the type of pragmatic relation and its stress made in one of its two counter parts 


\section{Psychology \& Psychological Research International Journal}

in the stages of both narratives are respectively a) the Conjunctive Relation (CR) that is presented with only its Continuous part stressed in the stage 4, 6, and 8. Such stress corresponds to $51 \%$ of incidence, according to the analysis. In the stage 5, however, the problematic pragmatic relation observed is the Substitution Relation in which its Extensive part is stressed in about 52\% over its Replaceable part [12]. The difference between the referential problems found by the Framework 3 to the referential problems in the Framework 4 is that the stress made along the pragmatic relations may be used perfectly to indicate how the hero's emotional shifts may influenced by the way the emotion types are distributed in the narrative. Therefore, it is important to point out the missing emotion types for the hero's full conduct development in the narrative. As such, through the figure 6below is possible to identify not just the referential problems highlighted in the M.H.J. stages, but also identify how the problems as to pragmatic relation affects the spread of emotive signs of the towards that what is to form his main psychological conduct along the journey. The stages 1,2, 3, which are not indicated previously as having any pragmatic relation problem, demonstrate now that lack of certain types of emotion. Stage 1 lacks Social Emotion (SO) and Basic Emotions (BA) while the frequency of incidence for the Background Emotion (BG) remains stable within which the analysis considers as a number of normality. However, in the stage 2 occurs the opposite as the only missing emotion type is a BG type. The same happening to the stage 1 , it happens again in the stage 3 where SO and BA are missing in the narrative $[12,22]$

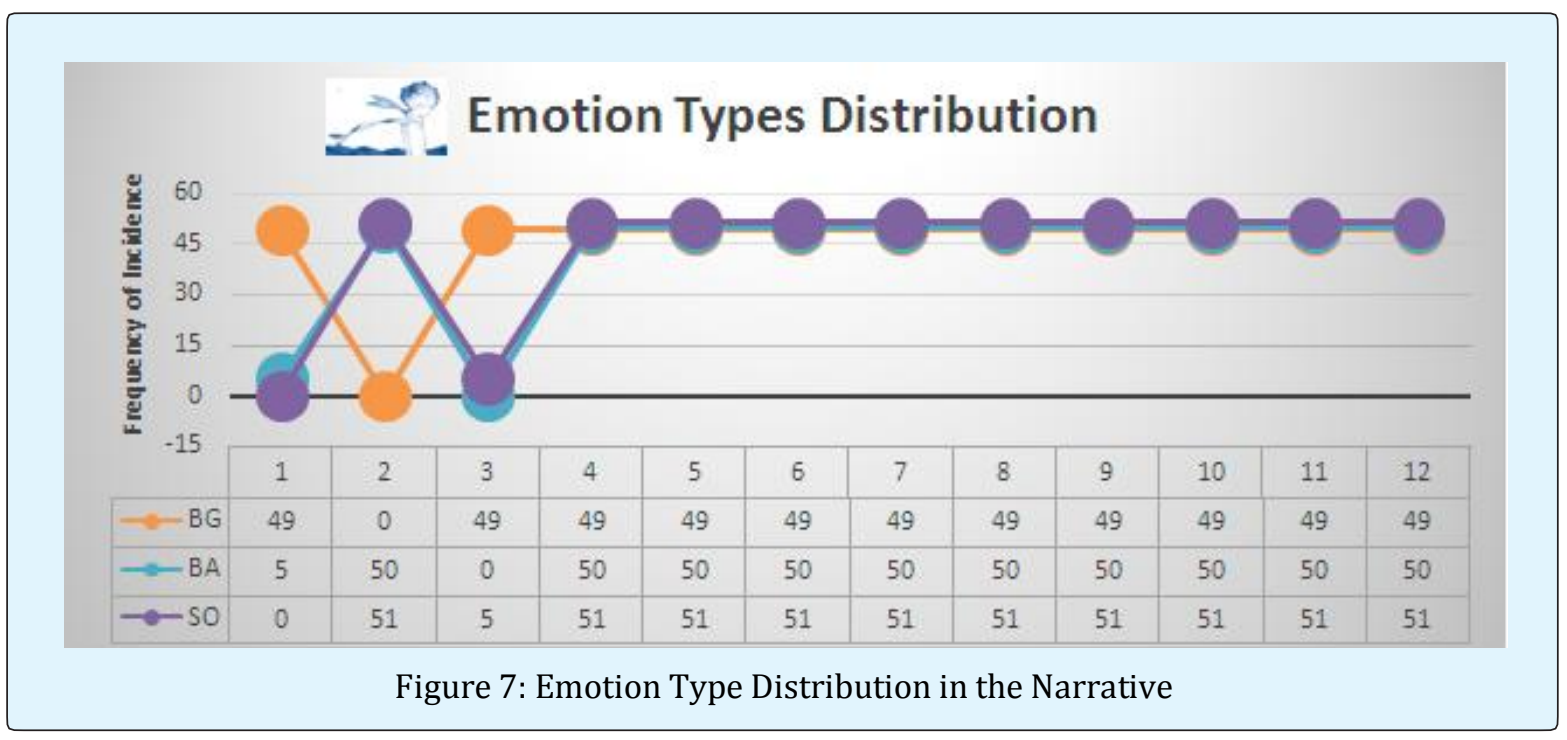

\section{Discussions}

The referential problems identified in the literary and audiovisual texts from the story of the Little Prince is clear, especially when those affect children during the intuitive age. Although the referential problems identified do not represent a big impact for the overall understanding of the story, those do still exist somehow. It is not new the complaints made by parents and educators about children's literary and audiovisual texts that are not integrally destined to children's communicative process. However, to point out the existence of a perfect text sounds quite $u$ topic and useless for the purpose of this work. Thus, which rather than trying to show textual perfections, this article discuses on how to show the textual imperfections that may influence the overall conceptualization process in children's intuitive age group. Therefore, to begin with, if you will, it is important to say that it does not matter how prestigious the author or the text is in the audience's mind. The major importance hereafter is the text itself, as well as all its intercrossing elements that form its texture. Perhaps, the two major intercrossing elements of any given text are the subject and the context, for those are responsible to give the text sense of a good or bad reading experience. The Little Prince is a classic narrative, which perhaps contains one of the most acknowledged stories among children's text ever. However, it is not a perfect text. Such affirmation means to be positive, for children's text. Children's texts as any other literary text should not be seen as static or enclosed material locked up in itself. Moreover, literary children's text is to be dynamic and open for outer influences that should join strength in further readings. The Little Prince's story has that sense of movement and freedom in its text. According to our analysis, the referential problems among children's intuitive age may exist even in well-known texts such as that. The qualification and categorization of such 


\section{Psychology \& Psychological Research International Journal}

referential problems found between both versions of the narrative of Little Prince (literary and audiovisual) indicates the importance for the type of identification process made by children. The hero was and has been the main archetypal character of any child's story. For the hero embodies audience's aspiration and vital sense of ethics, the satisfaction of key psychological functions need to function in a well and controlled manner. Along with children's intuitive age, such psychological functions are classified by the analysis over the text of the story about the adventure of the Little Prince. Thus, along the four frameworks of analysis, at least one important aspect of children's psychological needs is not entirely dealt by the text at any stage of the hero's journey. Be it in the literary or in the audiovisual text, such missing psychological function corresponds to one of our Children's Main Intuitive Conceptual Category described by the Philosophy and Religious Sense. Consequently, once the texts analyzed do not make any reference for such intuitive conceptual category for the satisfaction of children's psychological needs, all its Set of Intuitive Concepts are also absent in the narrative. From that perspective, the first set of referential problems may occur along the reading process of the text. By a reading process we understand as a cognitive and active effort made from the multitudinous amount of linguistic signs towards a complex realization of meaningful senses that are, ultimately, promoted by emotions and feeling. It is a pragmatic understanding of the term "reading" that is used here [20,21,23]. For some important intuitive concepts belonging to such intuitive conceptual category are not present in the narrative, the psychological satisfaction is interrupted. The missing conceptual references related to such intuitive conceptual category are as follow: the humanity origin, celestial creation, the father god, death, god as human, age and time, instantaneity, legends and myths. At this point, it is key to say that authors are free to tell their stories and that not all concepts have necessarily to be present in the narrative, but it should be reasonable if they were somehow mentioned, as we think of children's psychological needs and their referential problems [24, 25].

Another type of referential problems found through the framework 2 as to the theory of magic realism accused a slight interference on the text. . Thus, after revising the contents of both the literary and the audiovisual texts, only the literary narrative demonstrated lack of artificiality concepts, which belongs to the group of the three prime intuitive concepts (animism, finalism, and artificialism). Such interference is mentioned here only because of the type of referential problem it represents. For artificialism is one the major aspects of the primitivist aesthetics that is inherent to all children's literature, the literary text misses this important aspect of children's intuitive conceptualization. That is true especially as we compare tacitly such referential problem to the lack of Philosophy and Religious Sense pointed out by our Children's Main Intuitive Conceptual Category yet in the first section of framework 2. It seems that the referential problems within framework 2 generated consecutive referential problem of the same kind, but with a different format that needed to be identified separately as we did in the second section of the framework 2. Therefore, without the reasonable artificilistic conceptualization the literary text presented some referential problems in the beginning of the stages of the literary version of the story. However, such problem seems to be fixed on the audiovisual version. For the story passed through a medium translation, the audiovisual version shows some dialogues and images that correspond to artificialism. For this reason it reasonable to say that the stories are not just different but also qualitatively either better or worse, according to the referential problems identified.

The rest of referential problems identified by the framework 2 are those ones related to the other topic presented by the theory of Children's Magic Realism [12] from which the only missing primitivist concepts are some of the pictorial elements pointed by Menton (1999) [18]: the "Ultra-Precise Focus", "Frigidity", and the Elimination of the Painting process. Nonetheless, the referential problems identified base themselves on a lack of some prime intuitive concepts rather than the magical element of the theory; so that, the missing conceptualization of the prime elements represented crucial intuitive references for complete Children's Conduct Characteristics (C.C.C.) in the intuitive age group. Ultimately, the magic realism aesthetic presented in the narrative of the Little Prince in both versions (literary and audiovisual) could be included pragmatically as having its aesthetical elements connected to both inner and outer facts of reality affecting the narrative [4,7,15-27]; besides, both stories can be considered as a true child-oriented narratives. Therefore, the intuitive age group is greatly encompassed as the main receptors of the moral messages of the story regardless the missing concepts that disturbed the treatment for basic intuitive concepts towards a full satisfaction of children's psychological needs described in the analysis.

Consequently, it should be of great importance the application of the primitivist aesthetic in child's narratives for reducing the amount of referential problems and increase child's psychological satisfaction in face of their needs. The lack of a strong intuitive conceptualization may lead up children to weak cognitive 


\section{Psychology \& Psychological Research International Journal}

envelopment, for children's intuitive thoughts need to be refined through processes that consider the construction of the object, so the use of metaphors might include process affecting children's assimilation, accommodation, and reasonable response to causality, the humanity origin, celestial creation, the father god, death, god as human, age and time, instantaneity, legends and myths. In another words, it may be advantageous for authors to take seriously the conceptual category related to Philosophy and Religious Sense into account in order to get in contact with children's intuitive age specific aesthetic principles, otherwise children may incur frustration, or even lack of attention for they are not quite likely to represent literary information in the rational fashion as adults do it so $[3,7,28]$. Because the intuitive age group is a special period in children's ethical and philosophical sense, it should be naturally stimulated its representation in the narrative by natural phenomena, such as the wind, storm, nightfall, rain and many others which are so unique and vivid in children's imagination. To the same extent, curiosity in children's intuitive age is not just a matter of enjoyment, but also a matter of psychological development that demands accommodation for their questions. That is why a strong conceptualization process regarding both children's magic realism may be of great benefit for children's intuitive conceptualization, ultimately for the satisfaction of child's psychological needs. Once again, the application of primitivist aesthetic found in the mythological hero's journey, magic realism theory, function of emotion and the pragmatic relations in children's intuitive age, proved being efficient to identifying children's referential problems in the Little Prince's story. Therefore, this method of analysis may be used for other child's materials and authors worldwide as the essential part of analysis is contained in proper texts. Consequently, it has been inferred that when a stage comes out full of magic concepts, it will become crucial to not just present quantified information about such concepts, but also to present qualified information regarding the integration between magic conceptualization and children's intuitive age group, as it can be of great benefit for children's intuitive conceptualization, mainly because it does not offer adult's concepts, in which could lead up to either violent scene to depict the notion of struggle for survival, or to any kind of stereotypes to depict the hero's enemies. For instance, as the first and second frameworks are put together, it is also possible to notice that they both allow not only the identification of the stages along the percentiles, but also allows the identification for missing magic concepts along the three-act dramatic structure. As a result, the missing concepts may be considered as responsible to influence negatively children's intuitive conceptualization process in both narratives, which ultimately may lead up to children's referential problems towards an overall communicative process along the stories. Thus, for the first act of both narratives does not present enough magic concepts, the narrative tends to not immerse children into their own conceptual environment, thereby disturbing children's overall assessment of the following concepts in the other acts and stages. The beginning of the story in children's magic realism is crucial for children's intuitive referential assessment over magic concepts. It is therefore a different conceptualization process from the adult's at this point, because it does not depend on a linear and rational format, but otherwise it deal with non-linearity and irrational thinking connected to emotions, intuitions and imagination. Thus, these three elements are what in fact determined children's true enjoyment and apprehension of the story. Furthermore, as Children's Conduct Characteristics (C.C.C.) in both narratives are qualified as L.U.R.E. (Figure 4), it reveals that the hero's development started from an Leveled conduct characteristic, passing through a Unleveled and Reserved conduct until it finally gets to an Expansive conduct characteristic towards children's magic conceptualization process. Therefore, what is observed with such conduct characteristic order (Leveled, Unleveled, Reserved and Expansive) is that the Little Prince emotional shifting does not cause referential problems for children, mainly because of the acronym a L.U.R.E. that carries out a well controlled dramatic C.C.C. That result familiar for children's intuitive age to identify with.

\section{Conclusion}

Children's referential problems may be found in any children's text regardless its prestige. Children's intuitive age group tend to be realize their sense of story by following the intuitive conceptual references left along the stages of hero's journey. If any prime intuitive concept is missing in the narrative, so it can provoke referential problems in a consecutive order affecting the overall understanding of the story and not satisfying children's main psychological needs. Referential problems may be found in classic texts as just as in any other regular children's literary and audiovisual text where it is possible to apply the four narratological frameworks, which together compound Children's Magic Realism Theory created and developed by the author of this article. Lastly, for the sense of story within children's intuitive age group operate mostly by means of emotions and imagination authors shall create an atmosphere of intimacy for children to firstly assess the values of heroism, secondly the primitivist context in which the hero is involved, and finally with the dialogue and other actions that all other archetypal characters are likely to perform along with the hero's journey. Therefore, authors 


\section{Psychology \& Psychological Research International Journal}

willing to dialogue with children through entertainment texts should take into account the limitation of children to rationally depict artistic concepts in order to avoid children's referential problems.

\section{References}

1. Green MC, Brock TC (2002) "In the mind's eyes: Transportation-imagery model of narrative persuasion". In Narrative impact: Social and cognitive foundations, pp: 315-343.

2. Bortolussi M (1987) Análisis teórico delcuento infantile. Madrid: Alhambra, pp: 160.

3. Dahl R (2009) Writing children's book: an author of classics reflects on what it takes to succeed in this genre: giving young reader what they want. Writer 122(9): 16-55.

4. Delgado, José Emanuel C (2006) Comentários filológicos sobre el realismo magico. Madrid: Arco SL.

5. Harris PL (2000) Understanding children's world: The work of the imagination. Oxford, UK: Blackwell.

6. Holub RC (2000) Reception theory. New York: Routledge, pp: 210.

7. Hunt P (2004) International Companion encyclopedia of children's literature. New York: Rout ledge.

8. Valkenburg PM, Peter J (2004) "Fantasy and Imagination." In Psychology of Entertainment, edited by Jennings Bryant and Peter Vorder, New Jersey: Lawrence Erlbaum Associates, pp: 105-117.

9. Piaget J (2000) The Birth Of Intelligence In The Child, pp: 576.

10. Lev V (2004) Theory of emotions, Historicalpsychological study, translation by Judith Viaplana, Madrid, Akal.

11. Applebee NA (1978) The child's concept of story. Chicago: The University of Chicago Press, pp: 209.

12. Varela, Márcio Danilo M (2012) "Communicative Process between Children's Magical Realism Literature and Cinema: primitivist aesthetics for the referential problems in children's texts." PhD diss., Universityof Santiago de Compostela.

13. Varela MDM, Reis C (2016) "Primitivist Aesthetics for Identifying Child's Referential Problems: launching a new narratological methodology based on Monteiro
Lobato's Works". Weber Psychiatry \& Psychology 2-3: 578-586.

14. Hadjetian S (2015) Multiculturalism and magic realism in Zadie Smith's novel White Teeth: Between fiction and reality. Hamburg: Anchor Academic Publishing.

15. Faris WB (2004) Ordinary enchantments: magical realism and the remystification of narrative. Nashville, TN: Vanderbilt.

16. Campbell J (2005) El héroe de las mil caras. Madrid: Fondo de Cultura Económica. Pp: 241.

17. Vogler C (2004) The Writer's journey: mythic structure for storytellers and screenwriters. London: Pan Books.

18. Menton S (1999) Historiaverdaderadel realismo mágico. México: Fondo de cultura económica.

19. Rabinowitz PJ (2005) A companion to narrative theory. Malden, MA: Blackwell Publications, pp: 592.

20. Perriconi G (2008) Los niñostienenlapalabra: desde laadquisición de lalengua materna hasta el disfruto literário. Rosário: Homo Sapiens.

21. Guesell A (1998) El niño de 5 a 10 años. Barcelona: Novagràfik.

22. Damasio A (2007) En busca de Spinoza. Barcelona: Crítica.

23. López Félix, Etxebarria I, Rebollo MJF, Ortiz MJ(2005) Affective and social development, pp: 432.

24. Boruah BH (1988) Fiction and emotion: A study in aesthetics and philosophy of mind. Oxford: Claredon Press.

25. Bower MA (2004) Magi (cal) realism. New York: Routledge.

26. Camayd-F E (1998) Realismo mágico e primitivismo. Boston: University Press of America.

27. Doležel L (2010) Heterocósmica: ficción y mundos posibles. Madrid: Arcos.

28. Larkin-Lierffers PA (2010) "Images of childhood and the implied reader in young children's information books." Literacy 44(2): 76-82. 
29. Anthony Damasio (2006) Descartes' error: emotion, reason and the human brain. New York: Harper Collins Publishers Inc.
30. Zamorra, Lois Parkinson, Faris, Wendy B (1995) "Scheherazade's children: Magical realism and postmodern fiction", Magical realism theory, history, and community, pp: 169-170. 